University of Nebraska - Lincoln

DigitalCommons@University of Nebraska - Lincoln

One-Step Chromatographic Cleanup of Chlorinated Hydrocarbon Pesticide Residues in Butterfat. II. Chromatography on Florisil

William A. Moats

USDA-ARS

Follow this and additional works at: https://digitalcommons.unl.edu/usdaarsfacpub

Moats, William A., "One-Step Chromatographic Cleanup of Chlorinated Hydrocarbon Pesticide Residues in Butterfat. II. Chromatography on Florisil" (1963). Publications from USDA-ARS / UNL Faculty. 1654. https://digitalcommons.unl.edu/usdaarsfacpub/1654

This Article is brought to you for free and open access by the U.S. Department of Agriculture: Agricultural Research Service, Lincoln, Nebraska at DigitalCommons@University of Nebraska - Lincoln. It has been accepted for inclusion in Publications from USDA-ARS / UNL Faculty by an authorized administrator of DigitalCommons@University of Nebraska - Lincoln. 
Moats, William A.

ONE-STEP CHROMATOGRAPHIC CLEANUP OF CHLOR INATED HYDROCARBON PESTICIDE RESIDUES IN BUTTERFAT. II. CHROMATOGRAPHY ON FLORISIL Journal of the A.O.A.C. (Vol. 46, No. 2, 1963) 
Hoats, Willien A. 1963. One-atep chrcanetogruphic cleanup of chlortaoted hydrocerbon peaticide residues in butterfat. II. Chronatography on florisil. Reprinted from the Journal of the Association of Official Agricultural Chentsts, Vol. 46, April 


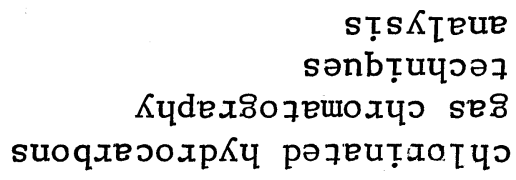


Moats, William A. 1963. One-step chromatographic cleanup of chlorinated hydrocarbon pesticide residues in butterfat. II. Chromatography on florisil. Reprinted from the Journal of the Association of Official Agricultural Chemists, Vo1. 46, April 


\section{One-Step Chromatographic Cleanup of Chlorinated Hydro- carbon Pesticide Residues in Butterfat. II. Chromatography on Florisil}

By WILLIAM A. MOATS (U.S. Department of Agriculture, Agricultural Marketing Service, Market Quality Research Division, Beltsville, Md.)

The procedure for chromatography on Florisil was modified by using methylene chloride-petroleum ether mixtures to improve separation of insecticides from fat. Combined with paper chromatography, it provides a screening procedure for insecticide residues in dairy products that is comparable in speed and simplicity to total chloride methods but is of superior sensitivity.

A previous paper (1) described the use of silicic acid for one-step chromatographic cleanup of some chlorinated hydrocarbon insecticides in butterfat. The silicic acid procedures, however, could be used with only a limited number of insecticides; they are not suitable as general screening tests. A number of other common adsorbents were, therefore, studied to develop a more generally applicable procedure. Florisil has proved to be the most generally satisfactory adsorbent for this purpose.

Florisil was used by Ordas, et al. (2) for chromatographic cleanup of heptachlor residues in alfalfa. Florisil columns were later used by Mills (3) and by McKinley and Mahon (4) as a cleanup step following acetonitrile partition in general screening procedures. Mills (3) reported difficulty in eluting kelthane and the aldrin group of insecticides from Florisil and had to use other types of columns for their cleanup. Mills (5) reported difficulty in obtaining good enough cleanup to permit spotting the entire sample for paper chromatography by Mitchell's procedure $(3,6)$.

In the present method, several modifications were made in the procedure for chromatography on Florisil to enhance its usefulness. The use of methylene chloridepetroleum ether mixtures, instead of $6: 94$ ethyl ether-petroleum ether used by other authors $(3,4,7)$ for elution, improves sepa- ration of insecticide from fat enough to permit direct chromatographic cleanup for paper chromatography of up to $2 \mathrm{~g}$ of butterfat. When the Florisil was deactivated slightly by adding water, it was possible to recover the aldrin group of insecticides satisfactorily.

This simple and rapid cleanup procedure, together with the paper chromatographic techniques of Mitchell $(3,6)$, provides a usable screening procedure for most common chlorinated insecticides that compares in speed and simplicity to total chloride methods (8) and at the same time is more sensitive and a good deal more informative.

\section{METHODS}

\section{Reagents and Equipment}

Petroleum ether.-30-60 $0^{\circ}$, redistilled.

Methylene chloride.-Reagent grade, redistilled.

Florisil. $-60-100$ mesh, activated at $1200^{\circ} \mathrm{F}$ (Floridin Company, Tallahassee, Fla.), standardized as described below.

Sodium sulfate.-Anhydrous, reagent grade, granular.

Butterfat used was obtained from commercial sources. E.S.A. standard insecticides were used except as indicated.

Equipment required is as described previously for chromatography in silicic acid (1). All stopcocks should be Teflon.

\section{Procedure}

Standardization of Florisil. - Heat Florisil overnight in an oven at $130-150^{\circ} \mathrm{C}$, transfer to tared screw-top jars, cool, and weigh. Add $5 \mathrm{ml}$ water/100 g Florisil, shake thoroughly, and allow to stand a day or two.

Check Florisil activity as follows: Fortify $0.5 \mathrm{~g}$ butterfat in $10-20 \mathrm{ml}$ petroleum ether with a few $\mu \mathrm{g}$ of DDT and methoxychlor. Prepare column of $25 \mathrm{~g}$ Florisil (about $5^{\prime \prime}$ ) in a $20 \times 400 \mathrm{~mm}$ chromatographic tube with coarse fritted glass disk, and top with about 1" anhydrous sodium sulfate. Wash with 50 $\mathrm{ml}$ methylene chloride and $50 \mathrm{ml}$ petroleum 
ether. Discard washings and put receiving flask in place. Add sample to column and, as soon as it has sunk in, rinse sample flask and inside of chromatographic tube with $10-20 \mathrm{ml}$ petroleum ether and add this to column. Elute with $75 \mathrm{ml} \mathrm{20 \%} \mathrm{v/v} \mathrm{methylene} \mathrm{chloride}$ in petroleum ether (fraction 1). Change receivers and elute with an additional $175 \mathrm{ml}$ $20 \%$ methylene chloride (fraction 2), collecting fractions in Erlenmeyer flasks of appropriate size.

To concentrate, add small boiling chip to sample flask, and boil in steam bath until only a few $\mathrm{ml}$ of liquid remains. (Boiling to dryness is not harmful, although prolonged heating of dry residue might cause some loss of insecticides.) Let flask cool, and transfer contents to a $15 \mathrm{ml}$ conical centrifuge tube. Rinse flask with few $\mathrm{ml}$ of petroleum ether and add to centrifuge tube. (Total volume in tube should not exceed $10 \mathrm{ml}$.) Add very small boiling chip. Place tip of tube in steam bath and adjust steam so that contents boil vigorously but without mechanical loss. Boil just to dryness and let tube cool. Use 0.1-0.2 ml liquid that condenses in bottom to spot for paper chromatography. To concentrate further, let tube stand open an hour or two. Use of an air stream at any stage in the concentration may cause serious loss of insecticides.

Run paper chromatograms, using Mitchell's nonaqueous system with dimethylformamide as immobile solvent and trimethylpentane as mobile solvent $(3,6)$. If insecticide spots tend to move with solvent front, as is frequently the case in the summer because of higher humidity, increase dimethylformamide concentration in dipping tank from $35 \%$ to 45 or $50 \%$. Spray and develop chromatograms as described by Eiduson (9). Let papers stand after spraying until they appear thoroughly dry before exposing to UV light. DDT should be all in fraction 1, methoxychlor in fraction 2 . Fraction 1 should give a light ring of fat when it is spotted; fraction 2 should show appreciably less fat. If these conditions are not met, repeat as above, using $15 \%$ methylene chloride to elute column.

Each new lot of Florisil received from the manufacturer should be standardized. It was not necessary to restandardize every fresh batch of Florisil prepared from a given lot. The material is stable for at least a month after processing as described.

\section{Preparation of Unknown Samples}

Butter-Melt butter in beaker and decant fat layer. Dissolve $2 \mathrm{~g}$ of the anhydrous butterfat in $30-40 \mathrm{ml}$ petroleum ether and proceed directly with chromatography.

Milk.-Extract as described by Mills (3) but in a separatory funnel. (Layers normally separate satisfactorily without centrifugation.) Evaporate or boil to dryness, take up residue in petroleum ether, and proceed with chromatography, using an aliquot equivalent to $\mathbf{5 0}$ $\mathrm{ml}$ original milk.

\section{Chromatography}

Pack $100 \mathrm{~g}$ Florisil into $40 \times 600 \mathrm{~mm}$ chromatographic tube and top with $1^{\prime \prime}$ anhydrous sodium sulfate. Proceed as described under Standardization, multiplying all amounts by 4 . For elution, use methylene chloride concentration (15 or $20 \%$ ) found to be satisfactory when Florisil was standardized.

\section{Recovery Experiments}

The procedure for unknowns was followed with $2 \mathrm{~g}$ butterfat fortified with $2-5 \mu \mathrm{g}$ of the insecticide. Recoveries were estimated by comparison with standard amounts of insecticide on the paper chromatograms. Several knowns were run at the same time where $R_{f}$ values permitted.

\section{Discussion}

The purpose of this study was to develop a one-step chromatographic cleanup technique suitable for separating a wide range of chlorinated hydrocarbon insecticides from fairly large amounts of fat. This together with paper chromatography would provide a fairly simple and rapid screening procedure. Paper chromatography requires quite rigorous cleanup for satisfactory results. Adsorbents examined with this idea in mind were silicic acid, activated alumina, decolorizing carbons, Florisil, and fuller's earths. The results with silicic acid have been reported previously (1). No worthwhile results were obtained with alumina. The last three adsorbents showed some promise, with Florisil being the most satisfactory.

Decolorizing carbons would also separate a large number of common insecticides from butterfat. Separation from fats was not as efficient as with Florisil, however, and this fact limited sample size. Some interfering material was washed off the carbon during elution. Despite these difficulties, decolorizing carbon may be useful for cleanup of 
such insecticides as Thiodan which cannot be completely recovered from other types of adsorbents.

Several commercial types of fuller's earth gave results rather similar to those obtained with Florisil, but the separations from fat were not as satisfactory.

In preliminary experiments, some lots of Florisil which had been on the shelf for over a year were used without reactivation. Elution with $20 \%$ methylene chloride in petroleum ether gave the most satisfactory separations of insecticides from fat (see Table 1). Methoxychlor was the most difficult to elute of the common insecticides. Dieldrin and endrin were eluted in somewhat less volume than methoxychlor. When the work was repeated with fresh and more active Florisil, the earlier results could be duplicated by increasing the concentration of methylene chloride in the eluting solvent to $40 \%$, except that dieldrin and endrin could not be recovered (Table 2). When Florisil was deactivated by adding $5 \mathrm{ml}$ of water per $100 \mathrm{~g}$ of Florisil, the earlier results could be reproduced. Mills (3), using carefully activated Florisil, also reported difficulty in recovering dieldrin and endrin. Johnson (7), using activated Florisil, found that a much higher concentration of ethyl ether was required to elute dieldrin and endrin than other chlorinated hydrocarbon insecticides and that separations from fat were not sufficient for paper chromatography.

Mills (3) also reported difficulty in eluting kelthane and aldrin from Florisil, although in the present work, they were recovered from even the more active lots without diffculty. He also reported poor recoveries of lindane, probably due to loss during evaporating samples under an air stream rather than failure to elute the material from Florisil.

The results of several determinations with the procedure adopted are shown in Table 3. Most recoveries were nearly quantitative. Only one isomer of Thiodan was recovered. Ovex ( $p$-chlorophenyl- $p$-chlorobenzenesulfonate) could also be recovered from Florisil but somewhat more than $1000 \mathrm{ml}$ of elutant was usually required. Thiodan alcohol and
Table 1. Chromatography on aged Florisil $(80$ g column, 2 g butterfat, 2-5 $\mu \mathrm{g}$ insecticides; eluting agent: $20 \% \mathrm{v} / \mathrm{v} \mathbf{C H}_{2} \mathbf{C l}_{2}$ in petroleum ether)

\begin{tabular}{l|rrrr}
\hline & \multicolumn{5}{|c}{$\begin{array}{c}\text { Estimated Recoveries }{ }^{a} \text { of Insecti- } \\
\text { cides by Paper Chromatography } \\
\text { from Indicated Fraction, \% }\end{array}$} \\
\cline { 2 - 6 } \multicolumn{1}{c}{ Insecticide } & $\begin{array}{r}\mid c-200 \\
\text { ml }\end{array}$ & $\begin{array}{r}200- \\
400 \mathrm{ml}\end{array}$ & $\begin{array}{c}400- \\
600 \mathrm{ml}\end{array}$ & $\begin{array}{r}600- \\
800 \mathrm{ml}\end{array}$ \\
\hline & & & & \\
Aldrin & $90-100$ & 0 & 0 & 0 \\
Chlordane & 100 & 0 & 0 & 0 \\
Lindane & 100 & 0 & 0 & 0 \\
DDE & 100 & & & \\
DDT & 100 & 0 & 0 & 0 \\
Endrin & 0 & 70 & 30 & 0 \\
Heptachlor & 100 & 0 & 0 & 0 \\
Heptachlor & & & & \\
$\quad$ epoxide & 40 & 60 & 0 & 0 \\
Ovex & 0 & 0 & 50 & 50 \\
Toxaphene & 100 & 0 & 0 & 0 \\
Kelthane & 20 & 80 & 0 & 0 \\
Methoxychlor & 0 & 40 & 60 & Tr. \\
Dieldrin & 0 & 60 & 40 & 0 \\
& & & & \\
\hline
\end{tabular}

a Estimated to $\pm 10 \%$.

Table 2. Chromatography on new Florisil (80 g column, 2 g butterfat, 2-5 $\mu \mathrm{g}$ insecticide;

eluting agent: $40 \% \mathrm{v} / \mathrm{v}$ methylene chloride in petroleum ether)

\begin{tabular}{|c|c|c|}
\hline \multirow[b]{2}{*}{ Insecticide } & \multicolumn{2}{|c|}{$\begin{array}{l}\text { Estimated Recoveries of } \\
\text { Insecticides by Paper } \\
\text { Chromatography from } \\
\text { Indicated Fraction, \% }\end{array}$} \\
\hline & $\begin{array}{c}0-600 \\
\mathrm{ml}\end{array}$ & $\begin{array}{c}600-800 \\
\mathrm{ml}\end{array}$ \\
\hline Aldrin & 100 & 0 \\
\hline Dieldrin & 0 & 0 \\
\hline Endrin & Tr. & 0 \\
\hline DDT & 100 & 0 \\
\hline DDE & 100 & 0 \\
\hline Methoxychlor & 100 & $\operatorname{Tr}$ \\
\hline Lindane & 100 & 0 \\
\hline Heptachlor epoxide & 100 & 0 \\
\hline Kelthane & 100 & 0 \\
\hline
\end{tabular}

a Estimated to $\pm 10 \%$.

2,4-D acid could not be eluted from Florisil.

All non-oxygenated chlorinated hydrocarbon insecticides were eluted completely in the first $300 \mathrm{ml}$. Oxygenated compounds required a somewhat larger volume. By 
Table 3. Chromatography on Florisil heated and deactivated with $5 \mathrm{ml}$ water $/ 100 \mathrm{~g}$ Florisil

(100 g column, $2 \mathrm{~g}$ butterfat, $2-5 \mu \mathrm{g}$ insecticides; eluting agent: 15 or $20 \% \mathrm{CH}_{2} \mathrm{Cl}_{2}$ in petroleum ether)

\begin{tabular}{|c|c|c|c|c|c|}
\hline \multirow[b]{2}{*}{ Insecticide } & \multirow{2}{*}{$\begin{array}{l}\text { No. of } \\
\text { Determinations }\end{array}$} & \multicolumn{4}{|c|}{$\begin{array}{l}\text { Estimated Recoveriesa of Insecticides by Paper Chromatography } \\
\text { from Indicated Fraction, \% }\end{array}$} \\
\hline & & $0-300 \mathrm{ml}$ & $300-600 \mathrm{ml}$ & $600-1000 \mathrm{ml}$ & Total Recovery \\
\hline Aldrin & 2 & 100 & 0 & 0 & 100 \\
\hline Chlordane & 1 & 100 & 0 & - & 100 \\
\hline DDE & 2 & 100 & 0 & 0 & 100 \\
\hline DDT & 3 & 100 & 0 & 0 & 100 \\
\hline Dieldrin & 4 & 0 & $50-90$ & $10-50$ & 100 \\
\hline Endrin & 1 & 0 & $\longrightarrow$ & 0 & 100 \\
\hline Heptachlor & 2 & 100 & 0 & - & 100 \\
\hline Heptachlor epoxide & 3 & 40 & 60 & 0 & 100 \\
\hline Kelthane & 4 & $30-50$ & $50-70$ & 0 & 100 \\
\hline Lindane & 4 & 100 & $0-\mathrm{Tr}$. & 0 & 100 \\
\hline Methoxychlor & 3 & 0 & 30 & 70 & 100 \\
\hline & & & $\longrightarrow$ & 0 & \\
\hline Thiodan & 1 & 0 & 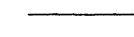 & $0^{b}$ & 100 \\
\hline Toxaphene & 1 & 100 & 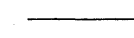 & 1 & 100 \\
\hline DDD & 2 & 100 & $\longrightarrow$ & 1 & 100 \\
\hline Ovex & 3 & 0 & -5 & $100-$ & $50-100$ \\
\hline
\end{tabular}

a Estimated to $\pm 10 \%$.

$\checkmark$ One component only.

collecting the eluate in two fractions, dieldrin, endrin, methoxychlor, and the one isomer of Thiodan were separated completely from the non-oxygenated insecticides. Heptachlor epoxide and kelthane were split between the $0-300$ and $300-1000 \mathrm{ml}$ fractions.

When butterfat was added, a characteristic blue band appeared at the top of the column, evidently produced from interaction of carotenes with Florisil. A similar reaction has been reported with carotenes and fuller's earth (10). The band spread out and faded during elution.

Because Florisil permits high flow rates through the column, this is a rapid procedure even though rather large volumes of solvent are used. Reducing the flow rate did not improve or alter the results; thus it is advantageous to use the maximum possible rate of elution. The cleanup, from preparation of the column to the time the sample is ready for paper chromatography, nor- mally required about 90 minutes, half of which was spent concentrating the eluate.

These results show the importance of steric factors in adsorption of some compounds. From the usual considerations of polarity and functional groups, one would not expect dieldrin and endrin to be adsorbed much more strongly than heptachlor epoxide, which also is a chlorinated compound with an epoxide grouping. This is the case with the less active Florisil. However, with the highly active material, dieldrin and endrin are much more strongly adsorbed than even methoxychlor, indicating that some peculiarity in the surface of the highly activated Florisil gives it a special affinity for dieldrin and endrin. Thiodan shows two components on paper chromatography, presumably isomers, only one of which can be recovered from Florisil. In earlier work, it was similarly observed that lindane was not readily eluted from silicic acid, although it was easily eluted 
from silicic acid-sulfuric acid mixtures and from Florisil. Again, it is necessary to refer to steric factors to explain these results.

For paper chromatography of samples cleaned up by this method, Mitchell's nonaqueous system using dimethylformamide and trimethylpentane $(3,6)$ was distinctly the most satisfactory of several tested. With this system, interfering materials moved with the solvent front, and fat in the sample had little or no effect on $R_{f}$ values. With the aqueous system, troublesome washing of papers is required and movement of insectide spots in samples is sometimes retarded relative to standard spots containing no fat, interfering with identification of unknowns. Compounds can usually be identified satisfactorily from paper chromatograms using the nonaqueous system and from their location in the eluate from the columns.

In summer, insecticide spots may move with the solvent front on paper chromatograms, probably because they absorb moisture from the air (11). This difficulty is readily overcome by increasing the dimethylformamide concentration in the dipping solvent to 45 or $50 \%$, or even higher, if necessary.

The technique for spraying and developing the insecticide spots is quite important if maximum sensitivity is to be obtained. All insecticides studied except toxaphene and perthane are readily detected at a level of $1 \mu \mathrm{g}$ on paper chromatograms and in many cases, a few tenths of a microgram may be detected. Toxaphene forms a streak and requires 2-3 $\mu \mathrm{g}$ to show up, while $5 \mu \mathrm{g}$ of perthane gives a barely visible spot. For a $2 \mathrm{~g}$ fat sample, then, $0.5 \mathrm{ppm}$ or less of most insecticides can be detected, and this should be adequate for screening purposes. For greater sensitivity a fat sample of suitable size can be carried through a preliminary acetonitrile partition as described by Mills (3) or by McKinley and Mahon (4) and then a final cleanup made on Florisil as described in the present paper, using a column of appropriate size.

\section{Conclusion}

Cleanup on Florisil columns followed by paper chromatography provides a rapid and broadly applicable screening method for insecticide residues in dairy products. The apparatus required is simple and inexpensive. This cleanup technique can probably be adapted for detection of residues in other food and agricultural products.

\section{Acknowledgment}

The author wishes to express his sincere thanks to W. E. Westlake and M. S. Schechter, Agricultural Research Service, United States Department of Agriculture, for providing samples of kelthane, DDD, DDE, Thiodan, and heptachlor epoxide for this study and to Niagara Chemical Division, FMC Corporation for providing a sample of Thiodan alcohol. The author also wishes to thank P. A. Mills, Food and Drug Administration, for his very helpful review of this paper.

\section{REFERENCES}

(1) Moats, W. A., This Journal, 45, 355 (1962).

(2) Ordas, E. P., Smith, V. C., and Meyer, C. F., J. Agr. Food Chem., 4, 444 (1956).

(3) Mills, P. A., This Journal, 42, 734 (1959).

(4) McKinley, W. P., and Mahon, J. H., ibid., 42, 729 (1959).

(5) Mills, P. A., ibid., 44, 171 (1961).

(6) Mitchell, L. C., ibid., 41, 781 (1958).

(7) Johnson, L., ibid., 45, 363 (1962).

(8) Koblitzky, L., Adams, H. R., and Schechter, M. S., J. Agr. Food Chem., 10, 2 (1962).

(9) Eiduson, H. P., This Journal, 44, 183 (1961)

(10) Lederer, E., and Lederer, M., Chromatography, 2nd Ed., Elsevier Publishing Co., Amsterdam, New York, London, Princeton, 1957, p. 66.

(11) Mills, P. A., Mimeo Release, Food and Drug Administration, Washington 25, D.C., December 30, 1959.

This paper was presented in part at the $142 \mathrm{nd}$ meeting of the American Chemical Society, Atlantic City, N.J., Sept. 12, 1962. Printed by permission of the American Chemical Society.

Reprinted from the Journal of the Association of Official Agricultural Chemists, Vol. 46, April 1963. 